San Jose State University

SJSU ScholarWorks

Master's Theses

Master's Theses and Graduate Research

Summer 2016

\title{
The Mediating Role of Psychological Empowerment on the Relationship Between Job and Personal Resources and Employee Engagement
}

Ian McAllister

San Jose State University

Follow this and additional works at: https://scholarworks.sjsu.edu/etd_theses

\section{Recommended Citation}

McAllister, Ian, "The Mediating Role of Psychological Empowerment on the Relationship Between Job and Personal Resources and Employee Engagement" (2016). Master's Theses. 4728.

DOI: https://doi.org/10.31979/etd.z89s-q6ff

https://scholarworks.sjsu.edu/etd_theses/4728

This Thesis is brought to you for free and open access by the Master's Theses and Graduate Research at SJSU ScholarWorks. It has been accepted for inclusion in Master's Theses by an authorized administrator of SJSU ScholarWorks. For more information, please contact scholarworks@sjsu.edu. 
THE MEDIATING ROLE OF PSYCHOLOGICAL EMPOWERMENT ON THE RELATIONSHIP BETWEEN JOB AND PERSONAL RESOURCES AND EMPLOYEE ENGAGEMENT

\author{
A Thesis \\ Presented to \\ The Faculty of the Department of Psychology \\ San José State University \\ In Partial Fulfillment \\ of the Requirements of the Degree \\ Master of Science
}

by

Ian McAllister

August 2016 
(C) 2016

Ian McAllister

ALL RIGHTS RESERVED 
The Designated Thesis Committee Approves the Thesis Titled

THE MEDIATING ROLE OF PSYCHOLOGICAL EMPOWERMENT ON THE RELATIONSHIP BETWEEN JOB AND PERSONAL RESOURCES AND EMPLOYEE ENGAGEMENT

by

Ian McAllister

APPROVED FOR THE DEPARTMENT OF PSYCHOLOGY

SAN JOSÉ STATE UNIVERSITY

August 2016

Dr. Megumi Hosoda

Department of Psychology

Dr. Nancy Da Silva

School of Management

Angelo Termine, M.S.M, M.B.A, C.E.O. New England Institute for Neurology and Headache 


\title{
ABSTRACT \\ THE MEDIATING ROLE OF PSYCHOLOGICAL EMPOWERMENT ON THE RELATIONSHIP BETWEEN JOB AND PERSONAL RESOURCES AND EMPLOYEE ENGAGEMENT
}

\author{
By Ian McAllister
}

Employee engagement is one of the most researched topics in the field of industrial and organizational psychology, mainly because it has been shown to be linked to many positive individual and organizational outcomes. Although past research has consistently shown that job and personal resources are related to employee engagement, little attention has been paid to understand the underlying mechanisms of such relationships. The present study hypothesized that psychological empowerment would be a mediator between job and personal resources (i.e. supervisor support, opportunities for growth, and core self-evaluations) and employee engagement. Using survey response data from 165 employees throughout several industries, results showed that psychological empowerment mediated the relationship between core self-evaluations and employee engagement. Furthermore, the psychological empowerment dimension of meaning mediated the relationship between all of these resources and employee engagement. These results suggest that meaning is an important mechanism leading employees with these resources to become engaged in their work. These results suggest that organizations should place employees in roles that align with their personal set of beliefs and values, and further research should be conducted on potential positive work outcomes of meaning. 


\section{ACKNOWLEDGEMENTS}

I would be remiss not to mention that the completion of this thesis would not have been successful without the help and support from others.

First and foremost, I would like to thank the members of my thesis committee for their continued efforts to help me improve my thesis. Dr. Megumi Hosoda has been a pleasure to work with. Her attention to detail in such a large process is truly amazing. Dr. Nancy Da Silva made large contributions to this thesis due to her methodological and analytical insights, which strongly influenced the findings of this study. Angelo Termine, a mentor to me for many years, was a continuing source of inspiration, having been through two Master's programs himself.

Second, I'd like to thank my parents. I consider myself extremely fortunate to not only have a mother and a father who care deeply about me and my success, but also a stepmother and a stepfather who feel the same way. Without the continued support and advice from my family, the thesis process would have been much more difficult. Their stories and successes inspire me to be my best on a daily basis. 


\section{TABLE OF CONTENTS}

LIST OF TABLES ...................................................................

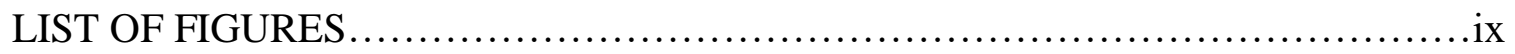

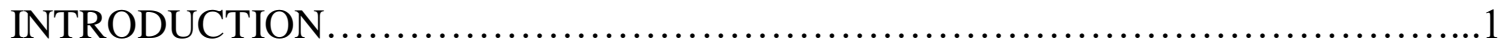

Employee Engagement and its Antecedents..................................4

Job Resources..................................................................

Personal Resources.......................................................

Psychological Empowerment as a Mediator of the Relationship Between Job and Personal Resources and Employee Engagement............................................9

Hypotheses.......................................................... 13

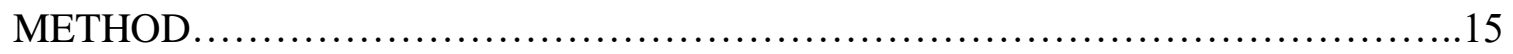

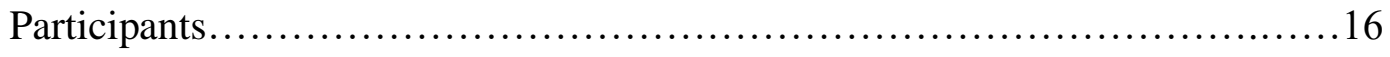

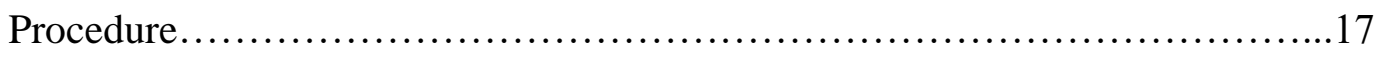

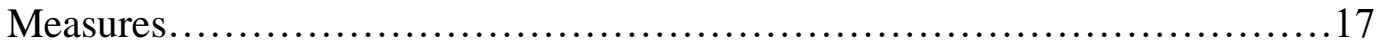

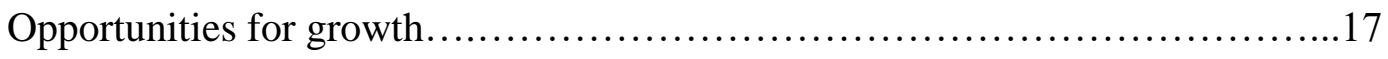

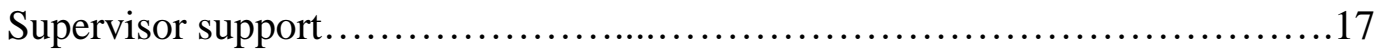

Core self-evaluations........................................................

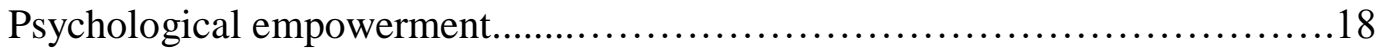

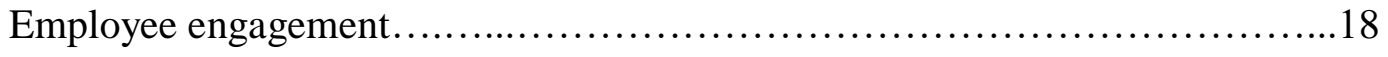

Demographic variables................................................... 19

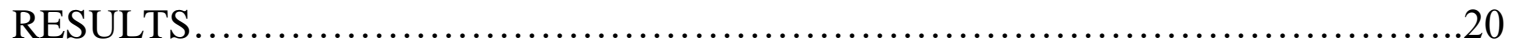

Descriptive Statistics..................................................20 
Pearson Correlations..................................................21

Test of Hypotheses............................................... 22

Supplemental Analyses.................................................25

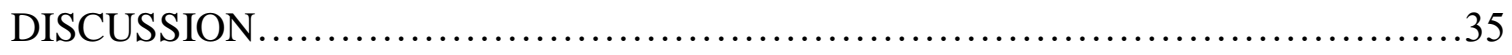

Theoretical Implications............................................. 38

Practical Implications ..............................................39

Strengths, Weaknesses and Future Direction for Research....................40

Conclusion......................................................42

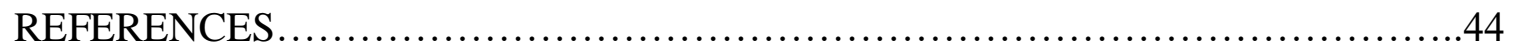

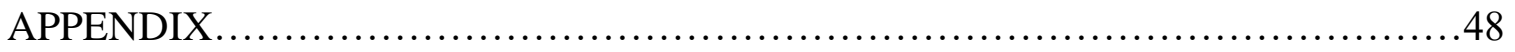

Survey Items...................................................... 48 


\section{LIST OF TABLES}

Table 1. Descriptive Statistics for Demographic Variables...........................16

Table 2. Means, Standard Deviations, Pearson Correlations, and Cronbach's Alphas....20

Table 3. Results of Mediation Analysis for Employee Engagement.................... 24

Table 4. Results for Supplemental Mediation Analysis Using Psychological Empowerment Dimensions and Supervisor Support....................... 26

Table 5. Results for Supplemental Mediation Analysis Using Psychological Empowerment Dimensions and Opportunities for Growth......................29

Table 6. Results for Supplemental Mediation Analysis Using Psychological Empowerment Dimensions and Core Self-Evaluations. 


\section{LIST OF FIGURES}

Figure 1. Hypothesized Relationships Between Job and Personal Resources and Employee Engagement.

Figure 2. Mediation Model for Employee Engagement................................25

Figure 3. Mediation Model for Employee Engagement Using the Dimensions of Psychological Empowerment as mediators and Supervisor

Support as a Predictor.................................................28

Figure 4. Mediation Model for Employee Engagement Using the Dimensions of Psychological Empowerment as mediators and Opportunities for Growth as a Predictor.................................................... 31

Figure 5. Mediation Model for Employee Engagement Using the Dimensions of Psychological Empowerment as mediators and

Core Self-Evaluations as a Predictor. 


\section{Introduction}

Employee engagement is one of the most researched topics in the field of industrial and organizational psychology, mainly because it has been shown to be linked to many positive individual and organizational outcomes. Employee engagement refers to a positive psychological state in which an employee is fully present in his or her work, and becomes focused on, and immersed in his or her tasks (Schaufeli \& Bakker, 2004). Engaged employees are invigorated, focused, and energized in their jobs, and feel as though time passes quickly at work (Macey \& Schneider, 2008; May, Gilson, \& Harter, 2004). Consequently, engaged employees have been found to have high levels of in-role and extra-role performance, are creative in their roles, are highly regarded by their coworkers, more committed to their organizations, and have less turnover intention (Bakker, Demerouti, and Verbeke, 2004; Gierveld \& Bakker, 2005; Xanthopoulou, Bakker, Demerouti, \& Schaufeli, 2007; Halbesleben, 2010). Furthermore, employee engagement has been shown to be positively related to business outcomes (e.g., profitability, customer satisfaction), and negatively related to employee turnover (Harter, Schmidt, \& Hayes, 2010; Roberts \& Davenport, 2002). It has been estimated that disengaged employees cost organizations in the United States hundreds of billions of dollars every year in terms of lost productivity (Crabtree, 2013). Given these positive outcomes of employee engagement and the financial ramifications of employee disengagement, researchers have paid considerable attention to identifying the antecedents of employee engagement. 
The job demands-resources (JD-R) model (Schaufeli \& Bakker, 2004) has been used to explain employee engagement. According to this model, the antecedents of employee engagement mainly fall into two major categories: job resources and personal resources. Job resources include a number of resources provided by an organization that benefit an individual in completing his or her job, such as autonomy, supervisor support, coworker support, and task significance (Schaufeli \& Bakker). Personal resources are positive self-evaluations that are linked to resiliency and refer to an individual's sense of his or her ability to control and impact upon his or her environment successfully (Bakker \& Demerouti, 2007). Studies have shown that job resources such as coworker support, autonomy, performance feedback, supervisory coaching, and personal resources such as self-efficacy, organization-based self-esteem, and optimism predict employee engagement (Saks, 2006; Xanthopoulou et al., 2007).

However, research on employee engagement has mainly focused on the examination of the antecedents of employee engagement. The potential psychological mechanisms underlying the relationship between resources and employee engagement have been studied much less frequently. An exception to this is a study by Quiñones, Van den Broeck, and De Witte (2013). They argued that psychological empowerment might mediate the relationship between job resources and employee engagement. Psychological empowerment is defined as intrinsic motivation manifested in four cognitions: meaning, competence, self-determination, and impact (Thomas \& Velthouse, 1990). Using social support from supervisors and colleagues, and skill utilization as job resources, Quiñones et al. tested whether psychological empowerment mediated the 
relationship between these resources and employee engagement, and found that job resources were directly and indirectly through psychological empowerment related to employee engagement.

Building upon Quiñones et al. (2013), this study examined whether psychological empowerment would mediate the relationship between other resources and employee engagement. This study used supervisor support and opportunities for growth as job resources, and core self-evaluations as a personal resource. Supervisor support is defined as the extent to which an individual receives job-related support from his or her supervisor (Karasek, 1979). Opportunities for growth refers to the extent to which an organization provides resources for employees to learn, grow, and develop as a professional such as promotions, formal learning, and development programs (Bakker \& Bal, 2010). Core self-evaluations are defined as beliefs that individuals hold about themselves and their capabilities, and are composed of four personality traits including generalized self-efficacy, emotional stability, locus of control, and self-esteem (Judge, Locke, \& Durham, 1997). These serve as important resources because opportunities for growth are likely to stimulate personal growth and development, supervisor support is likely to make employees feel competent, and core-self elevations play a large role in individuals' beliefs about their capabilities. Although these job and personal resources have never been studied as the antecedents of psychological empowerment, given that job and personal resources play an intrinsic and an extrinsic motivational role, it is not hard to imagine that individuals with these job and personal resources become psychologically empowered, which may in turn make them more engaged in their work (Bhatnager, 
2012). In other words, this study aimed to determine if employees who have personal and job resources become engaged in their work via psychological empowerment.

The current study makes several contributions to the literature. First, although job resources and personal resources have been positively related to employee engagement, the underlying mechanism behind these relationships has seldom been studied. This study investigated if psychological empowerment might be a potential mechanism underlying why resources are related to employee engagement. Second, this study extended Quiñones et al.'s study by including other job and personal resources to see if they also influence employee engagement through psychological empowerment. In particular, this study is the first study that examined whether psychological empowerment mediates the relationship between personal resources (i.e., core self-evaluations) and employee engagement. Furthermore, Quiñones et al.'s study was conducted in Chile, and is it not known whether their results are generalizable to western countries. The current study was conducted in a different cultural context, using participants from the United States. In sum, this study aimed to expand upon their research by using different antecedents and studying in a different cultural context.

The following section provides a definition of employee engagement, and a review of the literature on its antecedents. Furthermore, psychological empowerment is introduced as a potential mediator and the rationale for it is discussed. Finally, the hypotheses tested in the present study are presented.

\section{Employee Engagement and its Antecedents}


Employee engagement is defined as "a positive, fulfilling, work-related state of mind characterized by vigor, absorption, and dedication" (Schaufeli, Salanova, GonzalezRoma, Bakker, 2002, p. 74). According to Schaufeli et al., vigor is defined as high energy and mental resilience while working on tasks, absorption refers to becoming engrossed, focused, and immersed in one's work, and dedication is the aspect of an individual being highly committed to his or her work and having a sense of enthusiasm and significance towards his or her work. Thus, an engaged employee is focused on his or her work, has energy while working, and is personally dedicated to the outcomes of his or her work.

Although there exist other definitions of engagement, Schaufeli et al's definition has been the most widely used definition of employee engagement in the academic literature. Furthermore, their definition, as well as their scales, contribute to many of the major studies that have been conducted on employee engagement, models of employee engagement, and the antecedents and outcomes of employee engagement (Bakker, Schaufeli, Leiter, \& Taris, 2008). This definition of employee engagement also helps to capture the potential underlying mechanism behind the relationship between resources and employee engagement because resources activate a motivational process that leads to engagement. Using Schaufeli et al's definition and scales, research has demonstrated that the two major antecedents of employee engagement are job resources and personal resources.

Job resources. Job resources are defined as "those physical, psychological, social, or organizational aspects of a job that are (a) functional in achieving work goals; 
(b) reduce job demands and the associated psychological and physiological costs; and (c) stimulate personal learning, growth, and development" (Schaufeli \& Bakker, 2004, p. 296). Examples of job resources include task autonomy, performance feedback, social support, task variety, growth opportunities, and supervisory support (Schaufeli \& Bakker, 2004). According to the JD-R model (Schaufeli \& Bakker, 2004), job resources influence employee engagement because they serve an intrinsic motivational role and/or an extrinsic motivational role. Job resources play an intrinsic motivational role because they foster employees' growth and development, and help to fulfill basic human needs (need for relatedness, need for autonomy, and need for competence) (Schaufeli \& Bakker, 2004). Job resources play an extrinsic motivational role because they are instrumental in achieving work goals. In other words, with job resources, tasks will be completed successfully and work goals will be attained (Bakker \& Demerouti, 2008). Several studies have shown a positive relationship between job resources and employee engagement (Barbier, Hansez, Chmiel, \& Demerouti, 2013; Bakker \& Demerouti, 2008; Sarti, 2014; Xanthopoulou, Bakker, Demerouti, \& Schaufeli, 2009). For example, Barbier et al. (2013) found a positive relationship between opportunities for development and perceived supervisory/organizational support with employee engagement. Similarly, job control and supervisory support were found to be positively related to employee engagement (Bakker \& Demerouti, 2008). Sarti (2014) investigated the relationship between job resources and engagement among nurses, and job resources included learning opportunities, coworker support, and supervisor support. Results showed that all of these job resources were positively related to employee engagement. 
These studies show that the more job resources an individual has, the more engaged he/she will be.

Based on the results of these studies, it is clear that job resources are important antecedents of employee engagement. The current study examined two job resources: supervisor support and opportunities for growth. The current study looked at these two job resources because they have been studied less frequently compared to other job resources, such as task autonomy, performance feedback, and social support from coworkers. As mentioned earlier, supervisor support is defined as the extent to which an individual receives job-related support from his or her supervisor (Karasek, 1979). Opportunities for growth represents the extent to which an organization provides resources for an employee to learn, grow, and develop as a professional (Bakker \& Bal, 2010). Examples of opportunities for growth would be professional development training, or access to resources that help individuals improve and develop their skills.

Although supervisor support and opportunities for growth have not been studied as much as other job resources (e.g., autonomy, coworker support), there is empirical evidence that these resources are positively related to employee engagement. Sarti (2014) and Bakker and Demerouti (2008) both found that supervisor support was positively related to employee engagement. Although opportunities for growth has not been individually studied as an antecedent to employee engagement, many closelyrelated constructs have been studied in relation to employee engagement. For example, Barbier et al. (2013) found a positive relationship between opportunities for development and employee engagement, and Xanthopoulou et al., (2009) found a positive relationship 
between opportunities for professional development and employee engagement. Conceptually, any constructs pertaining to opportunities given to employees to develop their strengths or grow professionally will be similar. Given these findings, it is reasonable to assume that opportunities for growth would also be positively related to employee engagement.

Personal resources. Personal resources are positive self-evaluations that are linked to resiliency and refer to individual's sense of his or her ability to control and impact upon his or her environment successfully (Bakker \& Demerouti, 2007). Consistent with job resources, personal resources are "(a) functional in achieving work goals; (b) reduce job demands and the associated psychological and physiological costs, and (d) stimulate personal growth, learning, and development" (Schaufeli \& Bakker, 2004, p. 296). Research has shown that positive self-evaluations play a role in motivation based on how individuals view their own capabilities (Bandura, 1997; Judge, Locke, Durham, \& Kluger, 1998). In other words, when an individual is confident in his or her abilities and knows that the outcome of tasks are in his or her control, the individual will be more motivated to perform tasks. According to Luthans and Youssef (2007), individuals with high self-evaluations will have high self-regard and experience high levels of goal self-concordance. When an individual has high goal selfconcordance, he/she will become intrinsically motivated to complete tasks and goals because of the intrinsic reward provided by completing the tasks or the goals.

In addition to studying the effect of self-evaluations on employee engagement, personality traits have also been studied as a predictor of employee engagement. For 
example, Pocnet, Antonietti, Massuodi, Gyorkos, Becker, de Bruin, and Rossier (2015) investigated the relationship between the Big-Five personality traits and employee engagement, and found that neuroticism was negatively related to employee engagement, but conscientiousness, openness to experience, extraversion, and agreeableness were all positively related to employee engagement.

Several studies found a positive relationship between personal resources, such as self-efficacy, organization-based self-esteem, active coping behavior, and optimism, and engagement such that the higher employees' personal resources were, the more engaged they were at work (Bakker \& Leiter, 2010; Weigl, Hornung, Parker, Petru, Glaser, \& Angerer, 2010; Xanthopoulou et al., 2009). Xanthpoulou et al. also investigated how self-efficacy, organization-based self-esteem, and optimism acted as antecedents of employee engagement and found that these personality traits had a positive and significant relationships with employee engagement. These results indicate that personality traits could serve as personal resources at work. These relationship have been explained in terms of personal resources leading to motivation, which in turn leads to engagement (Bakker \& Demerouti, 2008). Because the current study assessed the underlying mechanisms leading employees with resources to become engaged, the aforementioned studies are important to draw upon because motivation, similar to psychological empowerment, has been shown to lead to engagement.

In this study, core self-evaluations were proposed to be additional personal resources that predict employee engagement. Core self-evaluations are defined as "fundamental premises that individuals hold about themselves and their functioning 
within the world" (Judge, Erez, \& Bono, 1998, p. 168) and are comprised of four personality traits: generalized self-efficacy, emotional stability, locus of control, and selfesteem (Judge, Erez, Bono, \& Thoreson, 2002). Self-esteem is an individual's overall feeling about himself/herself, and is a core self-value judgement (Harter, 1990). Generalized self-efficacy is an individual's belief in his or her own capabilities to take control in his or her life on a daily basis (Judge et al., 1997). Emotional stability refers to the extent to which an individual is consistent with his or her emotions and is not regularly anxious, timid, or insecure (Costa \& McCrae, 1998). Locus of control refers to an individual's beliefs about the extent to which he/she has control over his or her life (Rotter, 1966). An individual with an internal locus of control would believe that he/she has control over the events in his or her life, whereas an individual with an external locus of control would believe that an outside force or fate has control over the events in his or her life (Rotter, 1966).

Those with high core self-evaluations generally feel good about themselves and their capabilities, are emotionally stable and do not let small emotions bother them, and feel that they are in control of the outcomes in their life. Research has shown a relationship between core-self evaluations and employee engagement. For example, Jordan (2004) found a positive relationship between core self-evaluations and employee engagement. Although core self-evaluations have been shown to be related to employee engagement, it is not known why these variables are related. Therefore, the present study used core self-evaluations to see if psychological empowerment is the underlying mechanism relating core self-evaluations to employee engagement. 


\section{Psychological Empowerment as a Mediator of the Relationship Between Job and Personal Resources and Employee Engagement}

As mentioned earlier, although job resources and personal resources have been shown to predict employee engagement, little research attention has been paid to the examination of the potential mechanisms underlying these relationships. In this study, psychological empowerment is proposed to be a mechanism that explains the relationship between job and personal resources and employee engagement. Thomas and Velthouse (1990) defined psychological empowerment as intrinsic motivation manifested in four cognitions: meaning, competence, self-determination, and impact. In other words, when employees are psychologically empowered, they are creating an internal sense of motivation based on their cognitions regarding their work. Meaning reflects the value of the work goal or purpose in relation to an individual's own sets of beliefs, values, and standards (Thomas \& Velthouse, 1990; Spreitzer, 1995). Competence is an individual's belief in his or her ability to perform tasks successfully. Self-determination, which is also called 'choice,' refers to an individual's sense of control in beginning and maintaining actions. Impact, sometimes referenced as task significance, refers to the extent to which an individual's work can influence or change outcomes on the organizational level.

It is argued that supervisor support, opportunities for growth, and core selfevaluations are related to psychological empowerment. For example, supervisor support might bring meaning into individuals' work and increase their competence. Furthermore, if individuals are provided with opportunities for growth, they might feel that their organization cares about them, recognizes their potential, and increases autonomy (selfdetermination), which may lead them to complete tasks with greater enthusiasm. 
Likewise, those high on core self-evaluations strongly believe in their capabilities to perform their work and achieve competence in their tasks. The current study argued that because all of the previously mentioned resources lead to employee engagement, there must be an underlying reason why these relationships occurred. Building upon previous research, the current study proposed this underlying reason may be due to psychological empowerment.

Unfortunately, no research has examined supervisor support and opportunities for growth as antecedents of psychological empowerment. However, there is indirect evidence that shows that supervisor support and opportunities for growth might be related to psychological empowerment. For example, Seibert, Wang, and Courtright (2011) conducted a meta-analysis on the antecedents and consequences of psychological empowerment. They had contextual and individual characteristics as antecedents of psychological empowerment. Contextual antecedents included high-performance management practices, socio-political support, leadership, and work design characteristics, and individual characteristic antecedents included positive self-evaluation traits, human capital, and gender. Results showed that high-performance management practices, socio-political support, leadership, work design characteristics, and positive self-evaluation traits were all positively related to psychological empowerment. Examples of high-performance management practices include open information sharing, extensive training, decentralization of power, and participative decision making. Examples of socio-political support include justice perceptions, organizational climate, and organizational support. Examples of leadership include supervisor support, 
transformational leadership, and managerial behaviors. Examples of work design characteristics include job enrichment and task feedback. Examples of positive selfevaluation traits include core self-evaluations and generalized self-efficacy. Based on these findings, it is reasonably assumed that supervisor support, opportunities for growth, and core self-evaluations are also positively related to psychological empowerment.

When an individual is intrinsically motivated (i.e., psychologically empowered), it would make sense that he or she could easily become absorbed and energized about his or her work, hence engaged with his or her work. Unfortunately, Seibert et al.'s metaanalysis did not include employee engagement as a consequence of psychological empowerment. Furthermore, a surprisingly small amount of research has been done linking these two variables together. However, Bhatnagar (2012) found that psychological empowerment was a predictor of work engagement. Bhatnagar examined how employee engagement played a role in mediating the relationship between psychological empowerment with innovation and turnover intention. In other words, the author tested if employees who were psychologically empowered became more innovative and had less turnover intention because they were engaged in their work. Results of this study showed a positive and significant relationship between psychological empowerment and employee engagement. Although the study did not use psychological empowerment as a mediating variable, based on these results psychological empowerment clearly plays a role in engaging employees in their work. Furthermore, Macsinga, Sulea, Sarbescu, Fischmann, and Dumitru (2015) found that not only were psychological empowerment and employee engagement positively related, but 
that psychological empowerment predicted employee engagement above and beyond other predictors, such as personality traits and job tenure.

Given these findings, it is reasonable to assume that psychological empowerment acts as a mediator of the relationship between job and personal resources and employee engagement. In other words, when individuals have job and personal resources, they becomes more intrinsically motivated (i.e., psychologically empowered) to perform tasks, which lead them to be more engaged. However, few studies have examined psychological empowerment as a mediator of the relationship between job and personal resources and work engagement. As mentioned earlier, an exception to this is a study by Quiñones et al. (2013) who found that job resources (i.e., task autonomy, skill utilization, social support from supervisors and co-workers) were positively related to employee engagement via psychological empowerment. The purpose of Quiñones et al.’s study was to determine if employees with job resources would become engaged in their work because their job resources allowed them to become psychologically empowered. They gathered data from 1,300 Chilean public workers and found that psychological empowerment mediated the relationship between three of their job resources (task autonomy, skill utilization, social support from supervisors) and employee engagement. However, Quiñones et al. considered psychological empowerment as a personal resource. Unlike their study, the current study looked at psychological empowerment not as a personal resource, but as a cognitive state that may act as an underlying mechanism on the relationship between job and personal resources with employee engagement. 
Given that Quiñones et al.'s study is the only empirical study that examined the mediating role of psychological empowerment on the relationship between job resources and employee engagement, the present study built on their study by including whether psychological empowerment mediates the relationship between other job and personal resources and employee engagement. Therefore, the following hypotheses were tested:

Hypothesis 1: Psychological empowerment (meaning, competence, selfdetermination, and impact) will mediate the relationship between supervisor support and employee engagement.

Hypothesis 2: Psychological empowerment (meaning, competence, selfdetermination, and impact) will mediate the relationship between opportunities for growth and employee engagement.

Hypothesis 3: Psychological empowerment (meaning, competence, selfdetermination, and impact) will mediate the relationship between core selfevaluations and employee engagement.

Figure 1 presents a hypothesized model for resources, psychological empowerment, and employee engagement.

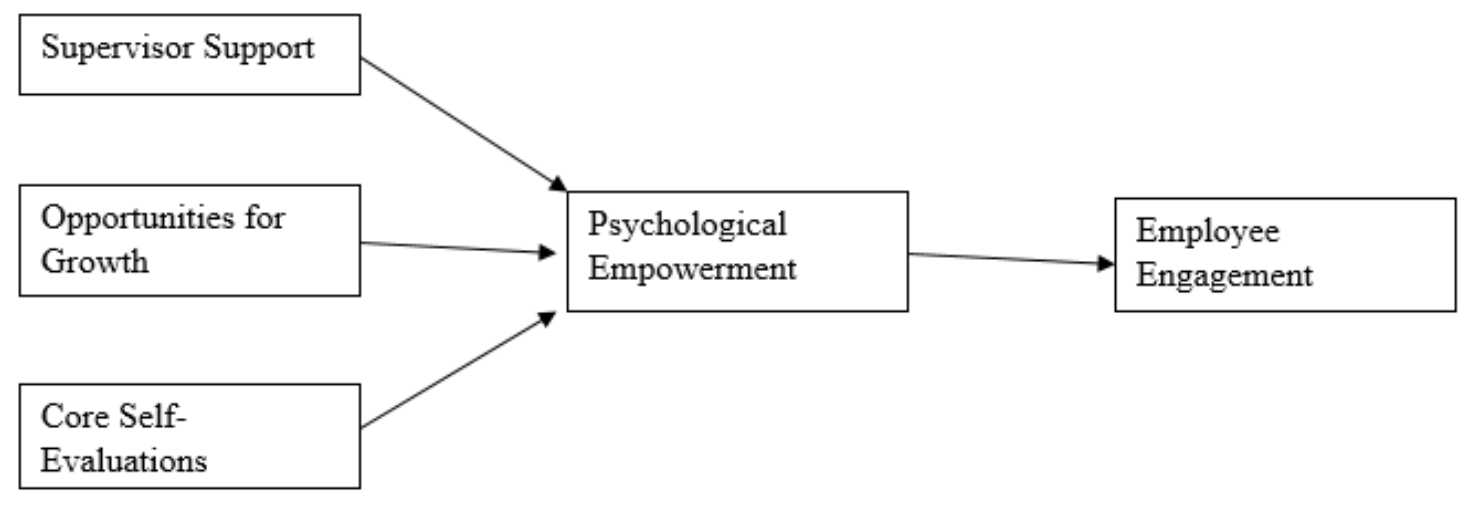


Figure 1. Hypothesized relationships between job and personal resources and employee engagement 


\section{Method}

\section{Participants}

There were a total of 186 participants in this study. Participants with large amount of missing data were excluded, resulting in the final sample of 165 participants. As will be mentioned below, data were collected through an online survey. Due to the use of public and private social media groups, a response rate was not able to be calculated.

Table 1 displays demographic information of the sample. Participants ranged in age from 21 years to 69 years, with an average age of 38.01 years $(S D=14.29)$. The sample consisted of $34.5 \%$ men $(n=57)$ and $64.8 \%$ women $(n=107)$. The majority of participants (79.4\%) identified themselves as White, followed by Hispanic/Latino (7.3\%), Asian (6.7\%), Black/African-American (1.2\%), Native Hawaiian/Pacific Islander (.6\%), and $4.2 \%$ reporting multiple ethnicities. One participant did not report his or her ethnicity $(.6 \%)$.

Participants worked in a variety of industries, including healthcare (20.6\%), education (13.3\%), technology (13.3\%), professional/business services (10.9\%), manufacturing (8.5\%), financial services/banking (5.5\%), and other industries such as retail, government, and media (27.9\%). On average, participants reported that they were employed at their current job for 4.81 years $(S D=7.31)$. Additionally, $82.2 \%$ of the sample were full-time employees, $12.9 \%$ were part-time employees, and $4.9 \%$ of the sample were contract/temporary workers. When asked if they supervised others in their current job, $30.3 \%$ of participants responded that they did, but $69.1 \%$ responded that they 
did not supervise others. Thus, a typical participant was a White women, working fulltime in a non-supervisory position, and had a job tenure of $4-5$ years.

Table 1

Descriptive Statistics for Demographic Variables $(N=165)$

\begin{tabular}{lrc}
\hline Variables & $n$ & $\%$ \\
\hline Age & $M=38.01$ & $\mathrm{SD}=14.29$ \\
Gender & & \\
$\quad$ Male & 57 & $34.5 \%$ \\
$\quad$ Female & 107 & $64.8 \%$ \\
Ethnicity & & \\
$\quad$ White & 131 & $79.4 \%$ \\
$\quad$ Hispanic/Latino & 12 & $7.3 \%$ \\
$\quad$ Asian & 11 & $6.7 \%$ \\
$\quad$ Two or more ethnicities & 7 & $4.2 \%$ \\
$\quad$ Black/African-American & 2 & $1.2 \%$ \\
$\quad$ Native Hawaiian/Pacific Islander & 1 & $.6 \%$ \\
$\quad$ No response & 1 & $.6 \%$ \\
Employment status & & \\
Full-time & 134 & $81.2 \%$ \\
Part-time & 21 & $12.7 \%$ \\
$\quad$ Contract/Temporary & 8 & $4.8 \%$ \\
$\quad$ No response & 2 & $1.2 \%$ \\
Industry & & \\
$\quad$ Healthcare & 34 & $20.6 \%$ \\
Education & 22 & $13.3 \%$ \\
Technology & 22 & $13.3 \%$ \\
Professional/Business services & 18 & $10.9 \%$ \\
Manufacturing & 14 & $8.5 \%$ \\
Financial services/Banking & 9 & $5.5 \%$ \\
$\quad$ Others & 44 & $27.9 \%$ \\
Supervisory position & & \\
$\quad$ No & 50 & $30.3 \%$ \\
$\quad$ No response & 114 & $69.1 \%$ \\
$\quad$ Job tenure & 4.81 & $\mathrm{SD}=7.31$ \\
\hline & &
\end{tabular}




\section{Procedure}

An online survey hosted on Qualtrics ${ }^{\circledR}$ was used to collect data. The survey link and a brief description of the research study were shared with the researcher's personal and professional connections via email and social media groups such as Facebook and LinkedIn. The targeted participants were encouraged to participate in the study and share the survey link and brief description with their connections.

Participants who clicked on the survey link were presented with a page containing the consent form, which described the purpose of the study and their responsibilities as a participant. They were then asked to indicate whether they consented to participating in the survey. Participants were presented two options at the bottom of the page, with one button saying "I consent," and another saying "I do not consent." Participants who clicked "I consent" were taken into the survey which measured their levels of employee engagement, psychological empowerment, core self-evaluations, opportunities for growth, supervisor support, and demographic information. Participants who clicked "I do not consent" were routed to the end of the survey. Once in the survey, consenting participants had the option to leave at any time by closing out of their web browser.

\section{Measures}

The variables in this study were all measured using a 5-point Likert scale. Responses ranged from 1 (strongly disagree) to 5 (strongly agree). The scores within each measure were averaged to create a composite score.

Opportunities for growth. Opportunities for growth were measured by a combination of Kraimer et al.’s (2011) Organizational Support for Development scale, 
and Bakker and Bal's (2010) Opportunities for Development scale. This 7-item scale contained statements regarding opportunities to grow and develop within the organization. Participants were asked to indicate their level of agreement for each statement. Sample items included "My organization has policies and programs in place to help employees advance in their functional specialization," and "My work offers me the opportunity to learn new things." Cronbach's coefficient alpha was .92.

Supervisor support. Supervisor support was measured by a combination of Cheng et al.'s (2015) Supervisor Support scale, and a modified version of the Perceived Supervisor Support scale developed by Swanberg et al. (2011). This 8-item scale contained statements regarding the different types of support an employee might receive from his or her supervisor. Participants were asked to indicate their level of agreement for each statement. Sample items included "My supervisor shows concern for me," and "My supervisor allows me to make decisions necessary to do my job well." Cronbach's coefficient alpha was .92 .

Core self-evaluations. Core self-evaluations were measured with the Core SelfEvaluations Scale (CSES) developed by Judge et al. (2003). This 12-item scale consisted of items assessing the way in which individuals felt about their personality, capabilities, and control over their lives. Participants were asked to indicate their level of agreement with each statement. Sample items included "When I try, I generally succeed," "Sometimes, I do not feel in control of my work," and "I am capable of coping with most of my problems." Cronbach's coefficient alpha was .84. 
Psychological empowerment. Psychological empowerment was measured with the Psychological Empowerment Scale developed by Spreitzer (1995). Spreitzer conceptualized psychological empowerment as consisting of four dimensions (meaning, self-determination, competence, and impact) combined additively for the overall empowerment construct. This 12-item scale consisted of items pertaining to an individual's motivation and abilities at work. Sample items included "I am confident about my ability to do my job," "I have significant autonomy in determining how I do my job," and "My impact on what happens in my department is large." Cronbach's coefficient alpha was .88 .

Employee engagement. Employee engagement was measured using the Utrecht Work Engagement Scale (UWES) developed by Scheufeli and Bakker (2003). This 15item scale consisted of items pertaining to states and emotions while working to which participants indicated their level of agreement with. Sample items include "At my job I feel strong and vigorous," "I find the work I do is full of meaning and purpose," and "I get carried away when I am working." Cronbach's coefficient alpha was .92.

Demographic Variables. Participants were asked to answer seven questions related to their demographics, including age, gender, ethnicity, employment status, length in current job, which industry they worked in, and whether or not they were a supervisor. 


\section{Results}

\section{Descriptive Statistics}

Table 2 shows the means, standard deviations, Cronbach's alphas, and Person correlations of the measured variables. Participants felt that they had moderately supportive supervisors $(M=3.81, S D=.80)$, that their organizations provided them with some opportunities for growth $(M=3.45, S D=.87)$, and reported their feelings about themselves as moderately positive $(M=3.68, S D=.54)$. Participants also reported moderately high levels of psychological empowerment $(M=3.88, S D=.64)$, and were moderately engaged in their work $(M=3.73, S D=.64)$.

Table 2

Means, Standard Deviations, Pearson Correlations, and Cronbach's Alphas $(N=165)$

\begin{tabular}{rlllllll}
\hline Variable & $M$ & $S D$ & 1 & 2 & 3 & 4 & 5
\end{tabular}

1. Supervisor support $\quad 3.81 \quad .80 \quad$ (.92)

2. Opportunity for growth

$\begin{array}{lll}3.45 & .87 & .57 * *\end{array}$

3. Core self-evaluations

3.68

.54

$.31 * * \quad .42 * *$

4. Psychological empowerment

3.88

.64

$.18 *$

$.19 * \quad .40 * *$

5. Employee engagement

3.73

.54

$.22 * *$

$.44 * *$

$.50 * * \quad .54 * *$

Note. ${ }^{*} p<.05, * * p<.01$. (two-tailed).

Reliability coefficients (Cronbach's Alpha) are shown on the diagonal. 


\section{Pearson Correlations}

As presented in Table 2, all predictors were positively related to employee engagement: supervisor support $(r=.22, p<.01)$, opportunities for growth $(r=.44, p<$ $.01)$, and core-self evaluations $(r=.50, p<.01)$. These relationships suggest that participants who had more support from their supervisors, had more opportunities for growth within their organization, and felt more positively about themselves and their capabilities were more likely to be engaged in their work. Among these three predictors, core-self evaluations had the strongest relationship with employee engagement.

Furthermore, all three predictor variables were positively related to each other. Supervisor support was positively related to opportunities for growth $(r=.57, p<.01)$ and core self-evaluations $(r=.31, p<.01)$, such that participants who had more supportive supervisors felt they had more opportunities for growth, and reported more positive feelings about themselves, and vice versa. Core-self evaluations were positively related to opportunities for growth $(r=.42, p<.01)$, such that participants who had more positive feelings about themselves and their capabilities felt that their organization provided more opportunities for growth.

Additionally, all predictor variables were positively related to psychological empowerment such that participants who had more supportive supervisors $(r=.18, p<$ $.05)$, had more opportunities for growth $(r=.19, p<.05)$, and felt more positively about themselves $(r=.40, p<.01)$ were more likely to be psychologically empowered. Again, core self-evaluations had the strongest relationship with psychological empowerment. Finally, psychological empowerment was positively related to employee engagement $(r=$ 
$.54, p=<.01$ ), such that employees who felt more psychologically empowered were more likely to become engaged in their work.

\section{Test of Hypotheses}

Hypotheses were tested using the MEDIATE macro (Hayes \& Preacher, 2014). This analysis estimates the total, direct, and indirect effects of predictors on an outcome variable through a mediating variable. Because MEDIATE macro has greater statistical power and increased performance comparted to other mediation analyses (e.g., Baron and Kenny method, the Sobel test), inferences concerning the relative indirect effects were analyzed using bias-corrected 95\% bootstrap confidence intervals (Quiñones et al., 2013). Bootstrap confidence interval estimates were based on 10,000 bootstrap samples.

With MEDIATE macro, indirect effects are significant only if zero is not within the bootstrap confidence interval (Hayes \& Preacher, 2014). In a mediation analysis, it is assumed that there is no interaction between the predictor(s) and the mediating variable, meaning that the effect of the mediator on the outcome variable is not dependent on the predictors (Quiñones et al., 2013). In order to test the possibility of interaction between the predictor and the mediator, MEDIATE uses the homogeneity of regression analysis, where a non-significant $p$ value indicates that there is no interaction between the predictors and mediator. The hypothesized model in this study simultaneously tested the influence of supervisor support, opportunities for growth, and core self-evaluations (predictors) on employee engagement (outcome variable) via psychological empowerment (mediator). 
Hypothesis 1 stated that psychological empowerment would mediate the relationship between supervisor support and employee engagement. Similarly, Hypothesis 2 stated that psychological empowerment would mediate the relationship between opportunities for growth and employee engagement. Likewise, Hypothesis 3 stated that psychological empowerment would mediate the relationship between core self-evaluations and employee engagement.

Looking at Table 3 for the mediation analysis, total effect of a variable consists of the sum of the direct effect of the predictor on the outcome variable, employee engagement, after controlling for the mediating variable, psychological empowerment, and the indirect effect of the predictor variable on employee engagement through the mediating variable (i.e., path ab is computed as a product of path a and path $b$ ). Because the relationship between the predictor variables and the mediating variable does not provide insight into the overall relationship, it is not reported in Table 3, but can be found in Figure 2. Results of the mediation analysis are shown in Table 3 and Figure 2. There was no statistically significant relationship between supervisor support $\left(a_{1}=.07, p=.35\right)$, and opportunities for growth $\left(a_{2}=-.03, p=.67\right)$, with psychological empowerment. However, participants who had more positive feelings of themselves and their capabilities had higher levels of psychological empowerment $\left(a_{3}=.44, p<.01\right)$. Those participants who had high levels of psychological empowerment were more engaged in their work ( $b$ $=.40, p<.01)$. Although supervisor support was not directly related to employee engagement $\left(c_{1}{ }^{\prime}=-.08, p=.21\right)$, opportunities for growth $\left(c_{2}{ }^{\prime}=.21, p<.01\right)$ and core self-evaluations $\left(c_{3}{ }^{\prime}=.28, p<.01\right)$ were still directly related to employee engagement. 
For the significance of indirect effects, results showed that a bias-corrected bootstrap confidence interval for the indirect effect of supervisor support (BC95\%CI: -.03 - .09) and opportunities for growth (BC95\%CI: -.07 - .05) included zero, indicating that psychological empowerment was not a significant mediator between either of these predictors and employee engagement. However, a bias-corrected bootstrap confidence interval for the indirect effect of core self-evaluations did not include zero (see Table 3), indicating that psychological empowerment was a significant mediator of the relationship between core self-evaluations and employee engagement (BC95\%CI: .07 - .30). This result means that those employees who had positive feelings about themselves and their capabilities felt psychologically empowered, which in turn led them to be engaged in their work.

Overall, these results show support for only Hypothesis 3, such that core selfevaluations were linked to employee engagement through psychological empowerment. Hypotheses 1 and 2 were not supported. However, opportunities for growth and core self-evaluations were still directly related to employee engagement. 
Table 3

Results of Mediation Analysis for Employee Engagement

BC Bootstrap 95\% CI

Total effect of IVs on employee engagement

Coefficient $\quad S E$

Lower Upper

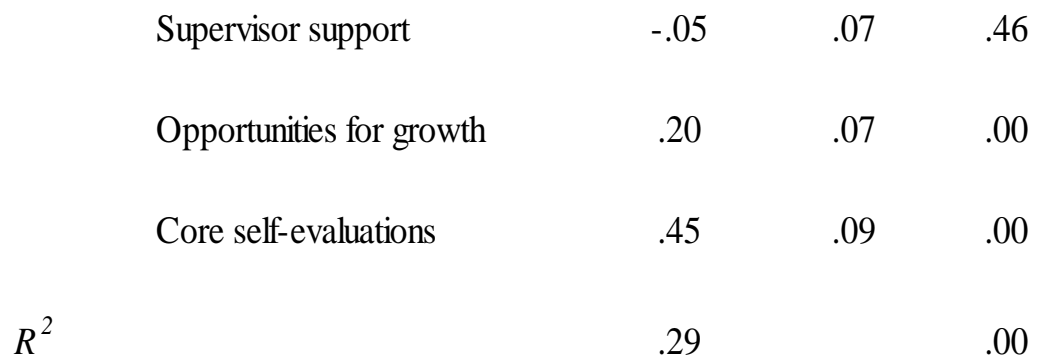

Direct effect of IVs on employee engagement

$\begin{array}{lccc}\text { Supervisor support } & -.08 & .06 & .20 \\ \text { Opportunities for growth } & .21 & .06 & .00 \\ \text { Core self-evaluations } & .28 & .09 & .00 \\ \text { Psychological Empowerment } & .40 & .07 & .00\end{array}$

$R^{2}$

.42

.00

Indirect effect of IVs on employee engagement through psychological empowerment

$\begin{array}{lcccc}\text { Supervisor support } & .03 & .03 & -.03 & .09 \\ \text { Opportunities for growth } & -.01 & .03 & -.07 & .05 \\ \text { Core self-evaluations } & .18 & .07 & .07 & .30\end{array}$

Homogeneity of regression test

\begin{tabular}{ccc}
$R^{2}$ & .01 & \\
$F$ & 26.89 & .00 \\
\hline
\end{tabular}

Note. $N=165$ 


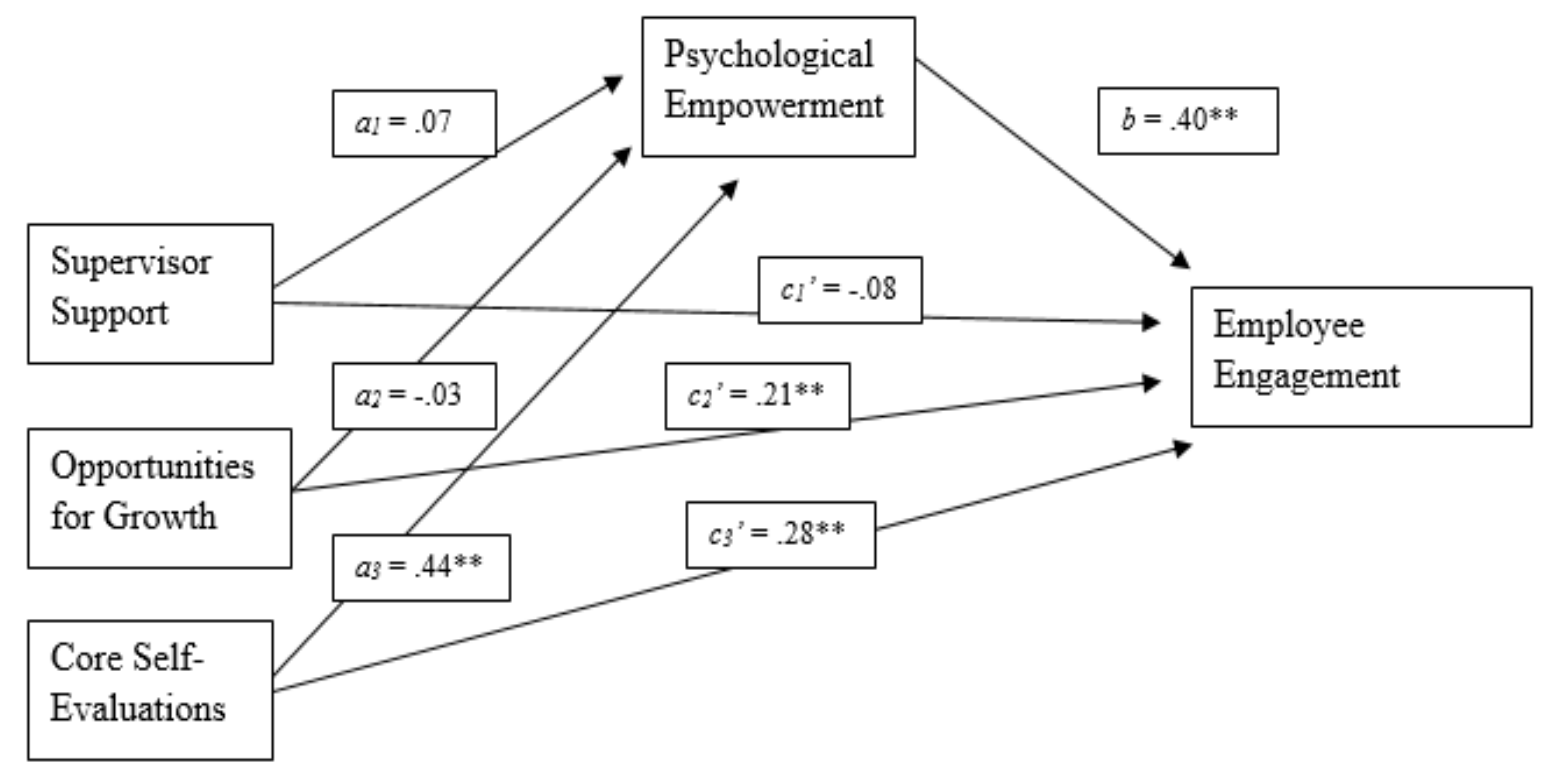

Figure 2. Mediation model for employee engagement

\section{Supplemental Analyses}

Because the initial mediation analysis did not support Hypotheses 1 and 2, additional exploratory analyses were conducted by decomposing psychological empowerment into four separate dimensions: meaning, impact, competence, and selfdetermination. These analyses were conducted to examine if supervisor support, opportunities for growth, and core self-evaluations would have an indirect effect on employee engagement through any of the four dimensions of psychological empowerment.

Table 4 and Figure 3 show the results of the mediation analysis with supervisor support as a predictor. Results show that those employees who had a more supportive supervisor had more amount of control over their work (self-determination) $\left(a_{4}=.33, p<\right.$ $.01)$. However, supervisor support was not significantly related to meaning $\left(a_{l}=.14, p=\right.$ 
$.06)$, impact $\left(a_{2}=.14, p=.22\right)$, or competence $\left(a_{3}=-.04, p=.58\right)$. Those participants whose work had high levels of meaning were more likely to be engaged $\left(b_{1}=.46, p<\right.$ $.01)$. There was no significant relationship of impact $\left(b_{2}=.05, p=.19\right)$, competence $\left(b_{3}\right.$ $=-.01, p=.91)$, or self-determination $\left(b_{4}=.05, p=.41\right)$ with employee engagement.

With respect to the significance of indirect effects, results showed that a biascorrected bootstrap confidence interval for the indirect effect of supervisor support through meaning did not include zero, indicating that meaning was a significant mediator between supervisor support and employee engagement (BC95\%CI: .01 - .15). This result indicates that employees who had a more supportive supervisor were more likely to feel that their work aligned with their personal beliefs and values, which made them become more engaged. The other dimensions of psychological empowerment included zero in their bias-corrected bootstrap confidence intervals, indicating that impact (BC95\%CI: .01 - .04), competence (BC95\%CI: -.03 - .01), and self-determination (BC95\%CI: -.01 .04) did not mediate the relationship between supervisor support and employee engagement.

Table 4

Results for Supplemental Mediation Analysis Using Psychological Empowerment Dimensions and Supervisor Support

\begin{tabular}{ccccc}
\hline & \multicolumn{3}{c}{ BC Bootstrap 95\% CI } \\
Coefficient & $S E$ & $p$ & Lower & Upper \\
\hline
\end{tabular}

Total effect of IVs on employee engagement

$\begin{array}{llll}\text { Supervisor support } & .16 & .06 & .00\end{array}$

$\begin{array}{lll}R^{2} & .05 & .00\end{array}$

Direct effect of IVs on employee engagement 


$\begin{array}{lccc}\text { Supervisor support } & .07 & .05 & .15 \\ \text { Meaning } & .46 & .05 & .00 \\ \text { Impact } & .04 & .05 & .19 \\ \text { Competence } & .01 & .06 & .91 \\ \text { Self-determination } & .05 & .06 & .41 \\ & & & \\ & .45 & & .00\end{array}$

Indirect effect of IVs on employee engagement through meaning

$\begin{array}{lllll}\text { Supervisor support } & .07 & .04 & .01 & .15\end{array}$

Homogeneity of regression test

\begin{tabular}{lrr}
$R^{2}$ & .00 & \\
$F$ & 1.93 & .17 \\
\hline
\end{tabular}

Indirect effect of IVs on employee engagement through impact
Supervisor support
.01
.01
$-.01$
.04

Homogeneity of regression test

\begin{tabular}{lll}
$R^{2}$ & .00 & \\
$F$ & .79 & .39 \\
\hline
\end{tabular}

Indirect effect of IVs on employee engagement through competence

$\begin{array}{llllll}\text { Supervisor support } & -.00 & .01 & -.03 & .01\end{array}$

Homogeneity of regression test

\begin{tabular}{lll}
$R^{2}$ & .02 & \\
$F$ & 5.08 & .03 \\
\hline
\end{tabular}

Indirect effect of IVs on employee engagement through self-determination 
Supervisor support

Homogeneity of regression test

$\begin{array}{cc}R^{2} & .00 \\ F & .03\end{array}$

Note. $N=165$
.03

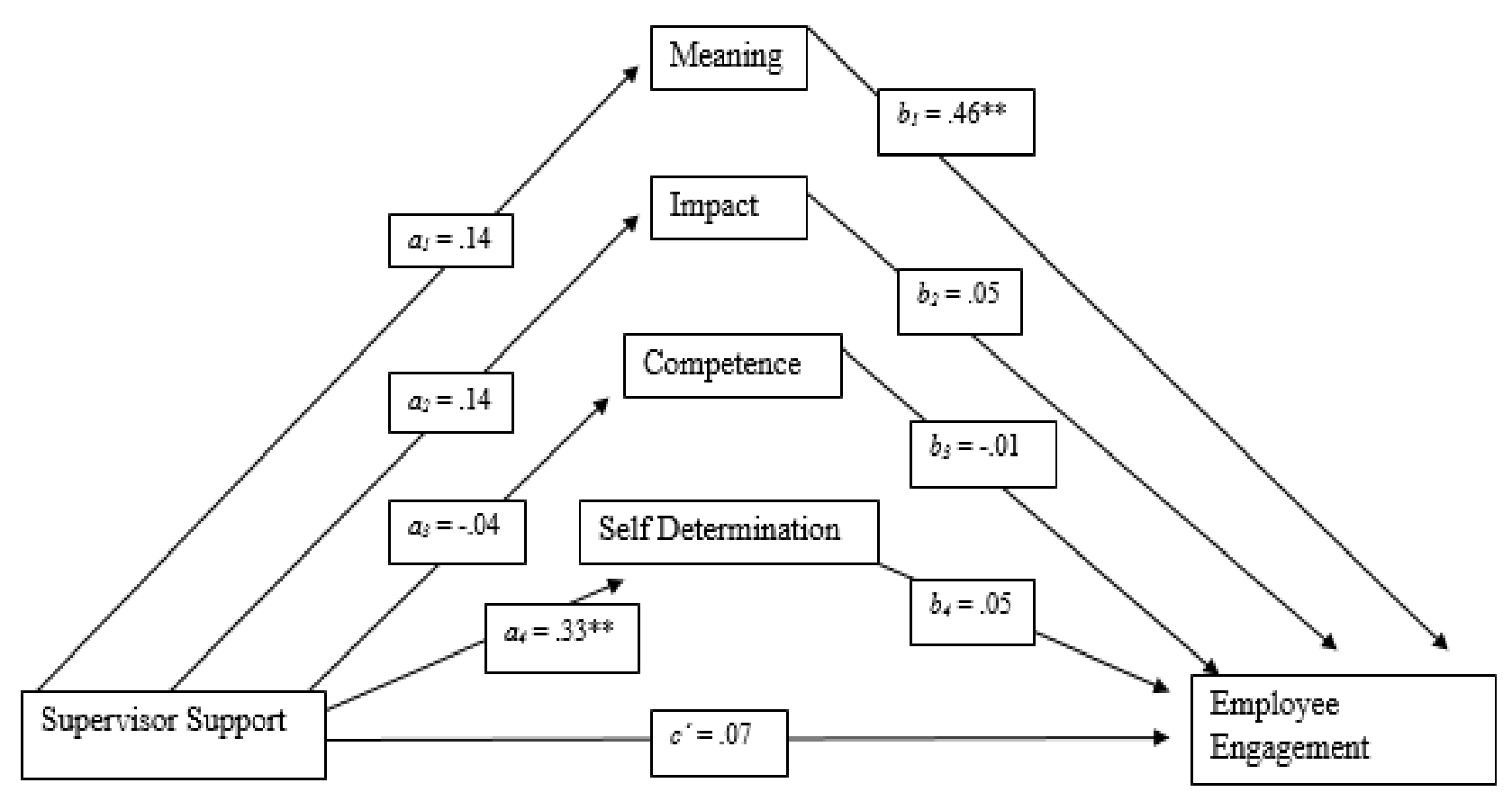

Figure 3. Mediation model for employee engagement using the dimensions of psychological empowerment as mediators and supervisor support as a predictor

Table 5 and Figure 4 describe the results of the mediation analysis with opportunities for growth as a predictor. Results show that those employees who felt that their organization provided more opportunities for growth felt that their work had higher levels of meaning $\left(a_{1}=.26, p<.01\right)$, and that their work had a greater impact on their department or organization $\left(a_{2}=.22, p<.05\right)$. There was no significant relationship 
between opportunities for growth and competence $\left(a_{3}=-.06, p=.34\right)$ or selfdetermination $\left(a_{4}=.12, p=.12\right)$. Among the four dimensions of psychological empowerment, those participants who felt that their work had higher levels of meaning and importance were more likely to be engaged $\left(b_{1}=.41, p<.01\right)$. However, the dimensions of impact $\left(b_{2}=.04, p=.35\right)$, competence $\left(b_{3}=.03, p=.68\right)$, and selfdetermination $\left(b_{4}=.06, p=.24\right)$ were not related to employee engagement. Furthermore, opportunities for growth were directly related to employee engagement $\left(c^{\prime}=.20, p<\right.$ $.01)$.

With respect to the significance of indirect effects, results showed that a biascorrected bootstrap confidence interval for the indirect effect of meaning did not include zero, indicating that meaning was a significant mediator of the relationship between opportunities for growth and employee engagement (BC95\%CI: .04 - .19). This result indicates that employees who felt their organizations provided more opportunities for growth were more likely to feel as though their work aligned with their personal values and beliefs, which led them to become more engaged in their work. The other dimensions of psychological empowerment included zero in their bias-corrected bootstrap confidence intervals, indicating that impact (BC95\%CI: -.00 - .03), competence (BC95\%CI: -.03- .01), and self-determination (BC95\%CI: -.01 - .04) did not mediate the relationship between opportunities for growth and employee engagement. 
Table 5

Results for Supplemental Mediation Analysis Using Psychological Empowerment Dimensions and Opportunities for Growth

\begin{tabular}{ccccc}
\hline & \multicolumn{3}{c}{ BC Bootstrap 95\% CI } \\
Coefficient & $S E$ & $p$ & Lower & Upper \\
\hline
\end{tabular}

Total effect of IVs on employee engagement

$\begin{array}{llll}\text { Opportunities for growth } & .32 & .05 & .00\end{array}$

$\begin{array}{lll}R^{2} & .19 & .00\end{array}$

Direct effect of IVs on employee engagement

$\begin{array}{llll}\text { Opportunities for growth } & .20 & .04 \quad .00\end{array}$

$\begin{array}{llll}\text { Meaning } & .41 & .05 & .00 \\ \text { Impact } & .04 & .04 & .35 \\ \text { Competence } & .03 & .06 & .68 \\ \text { Self-determination } & .06 & .05 & .24\end{array}$

$\begin{array}{lll}R^{2} & .53 & .00\end{array}$

Indirect effect of IVs on employee engagement through meaning

$\begin{array}{llllll}\text { Opportunities for growth } & .12 & .04 & .04 & .19\end{array}$

Homogeneity of regression test

$R^{2} \quad .01$

\begin{tabular}{lll}
$F$ & 1.93 & .17 \\
\hline
\end{tabular}

Indirect effect of IVs on employee engagement through impact

$\begin{array}{lllllll}\text { Opportunities for growth } & .01 & .01 & -.00 & .03\end{array}$

Homogeneity of regression test

\begin{tabular}{lll}
$R^{2}$ & .00 & \\
$F$ & .74 & .39 \\
\hline
\end{tabular}


Indirect effect of IVs on employee engagement through competence
Opportunities for growth
$-.00$
.01
$-.03$
.01

Homogeneity of regression test

$R^{2}$

F

Indirect effect of IVs on employee engagement through self-determination

Opportunities for growth

.01

.01

$-.01$

.04

Homogeneity of regression test

$R^{2}$

F

Note: $N=165$
.00

.03
.85

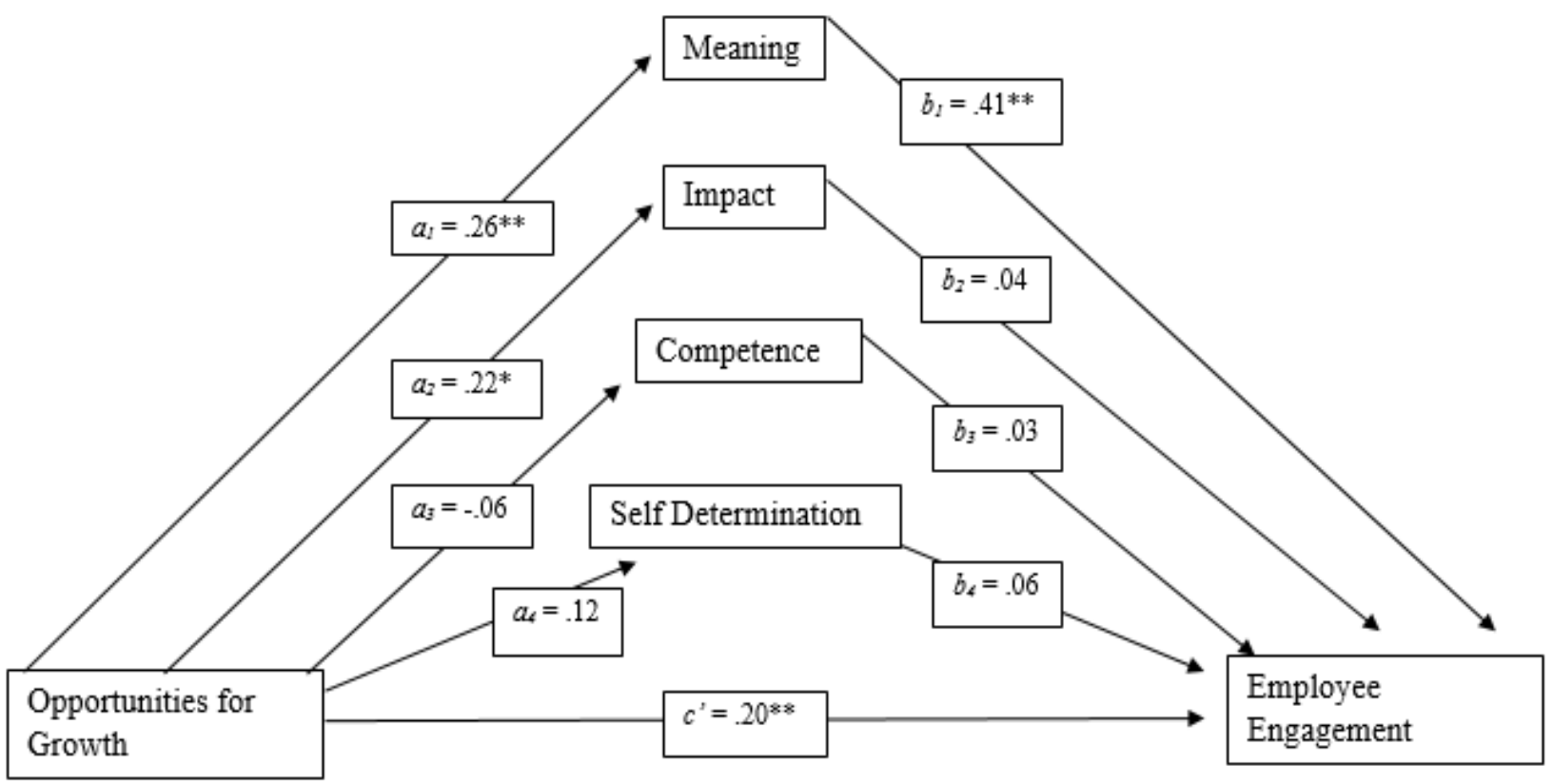


Figure 4. Mediation model for employee engagement using the dimensions of psychological empowerment as mediators and opportunities for growth as a predictor

Table 6 and Figure 5 describe the results of the mediation analysis with core selfevaluations. Results of the analysis showed that those employees who felt more positively about themselves and their capabilities felt that their work had higher levels of meaning $\left(a_{1}=.36, p<.01\right)$, that their work had a large impact in their department or organization $\left(a_{2}=.59, p<.01\right)$, were more confident in their ability to perform on the job $\left(a_{3}=.46, p<.01\right)$, and had a greater amount of control over how to do their work $\left(a_{4}=\right.$ $.46, p<.01)$. Among the four dimensions of psychological empowerment, those participants who felt their work had higher levels of meaning were more likely to be engaged in their work $\left(b_{1}=.44, p<.01\right)$. Interestingly, participants who had more control over how to do their job were less engaged in their work $\left(b_{3}=-.12, p<.05\right)$. Impact $\left(b_{2}=.03, p=.37\right)$ and self-determination $\left(b_{4}=.04, p=.36\right)$ were not related to employee engagement. Core self-evaluations were also directly related to employee engagement $\left(c^{\prime}=.42, p<.01\right)$.

With respect to the significance of indirect effects, results showed that a biascorrected bootstrap confidence interval for the indirect effect of meaning did not include zero, indicating that meaning was a significant mediator of the relationship between core self-evaluations and employee engagement (BS95\%CI: .05 - .28). This result indicates that employees who felt more positively about themselves and their capabilities were more likely to feel as though their work aligned with their beliefs and values, leading them to become more engaged in their work. The other dimensions of psychological 
empowerment included zero in their bias-corrected bootstrap confidence intervals, indicating that impact (BC95\%CI: -.02 - .07), competence (BC95\%CI: -.16 - .03), and self-determination (BC95\%CI: -.03 - .09) did not mediate the relationship between core self-evaluations and employee engagement.

In sum, the results of the supplementary analyses show that a dimension of meaning mediated the relationship between all of the job and personal resources and employee engagement. Furthermore, opportunities for growth and core self-evaluations are also directly related to employee engagement.

Table 6

Results for Supplemental Mediation Analysis Using Psychological Empowerment Dimensions and Core Self-Evaluations

\begin{tabular}{ccccc}
\hline & & \multicolumn{2}{c}{ BC Bootstrap 95\% CI } \\
Coefficient & $S E$ & $p$ & Lower & Upper \\
\hline
\end{tabular}

Total effect of IVs on Employee Engagement

$\begin{array}{llll}\text { Core self-evaluations } & .56 & .08 \quad .00\end{array}$

$\begin{array}{lll}R^{2} & .24 & .00\end{array}$

Direct effect of IVs on Employee Engagement

$\begin{array}{lccc}\text { Core self-evaluations } & .42 & .07 & .00 \\ & & & \\ \text { Meaning } & .44 & .05 & .00 \\ \text { Impact } & .03 & .04 & .37 \\ \text { Competence } & -.12 & .06 & .04 \\ \text { Self-determination } & .04 & .05 & .36 \\ & & & \\ & .55 & & .00\end{array}$

Indirect effect of IVs on Employee Engagement through Meaning

$\begin{array}{llllll}\text { Core self-evaluations } & .16 & .06 & .05 & .28\end{array}$

Homogeneity of regression test 


\begin{tabular}{lll}
$R^{2}$ & .00 & \\
$F$ & .44 & .51 \\
\hline
\end{tabular}

Indirect effect of IVs on Employee Engagement through Impact
Core self-evaluations
.02
.02
$-.02$
.07

Homogeneity of regression test

\begin{tabular}{lll}
$R^{2}$ & .00 & \\
& & \\
$F$ & .56 & .45 \\
\hline
\end{tabular}

Indirect effect of IVs on Employee Engagement through Competence
Core self-evaluations
$-.06$
.05
$-.16$
.03

Homogeneity of regression test

\begin{tabular}{lll}
$R^{2}$ & .02 & \\
$F$ & 5.13 & .02 \\
\hline
\end{tabular}

Indirect effect of IVs on Employee Engagement through Self-determination
Core self-evaluations
.02
.03
$-.03$
.09

Homogeneity of regression test

$R^{2}$

.01 


$\begin{array}{ccc}F & 1.81 & .18 \\ \text { Note }: N=165 & \end{array}$

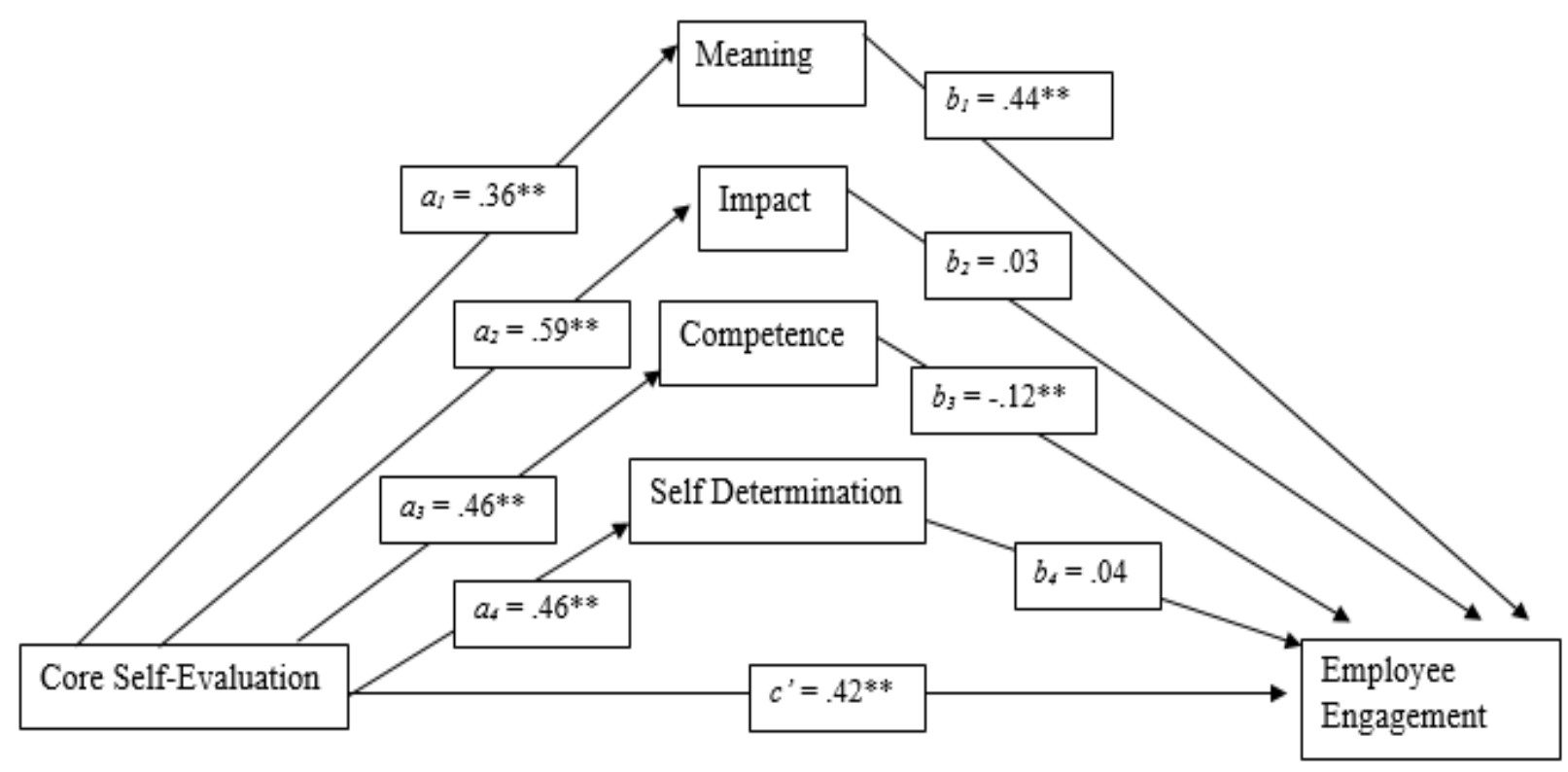

Figure 5. Mediation model for employee engagement using the dimensions of psychological empowerment as mediators and core self-evaluations as a predictor 


\section{Discussion}

Employee engagement is one of the most researched topics in the field of industrial and organizational psychology, mainly because it has been shown to be linked to many positive individual and organizational outcomes, including higher performance (Bakker et al., 2004) and lower employee turnover (Robert \& Davenport, 2002). Using the job demands-resource model (JDR) (Schaufeli \& Bakker, 2004), researchers (e.g., Bakker \& Bal, 2010; Barbier et al., 2013; Sarti, 2014; Xanthopoulou et al., 2007) have examined job and personal resources as predictors of employee engagement, but they have neglected to examine the potential mechanisms of the relationship between such resources and employee engagement. An exception to this is a study by Quiñones et al. (2013), who found that psychological empowerment mediated the relationship between job resources (task autonomy, skill utilization, and social support from supervisors) and employee engagement. Quiñones et al. called for more studies that would examine the potential mediators of the relationship between resources and employee engagement. Building on their study, this study proposed psychological empowerment as a mediating variable of the relationship between two lesser studied job resources (supervisor support and opportunities for growth) and a personal resource (core self-evaluations) with employee engagement. In other words, this study tested the hypothesis that if employees were provided with job and personal resources, they would become engaged in their work because they were psychologically empowered.

Hypothesis 1 stated that psychological empowerment (meaning, competence, selfdetermination, and impact) would mediate the relationship between supervisor support 
and employee engagement. The results of this study did not support Hypothesis 1 . Supervisor support was not related to employee engagement through psychological empowerment. Although results of bivariate relationships showed that supervisor support was positively related to both psychological empowerment and employee engagement, the inclusion of psychological empowerment in the mediation analysis showed that supervisor support was not related to psychological empowerment nor to employee engagement. However, given that supervisor support is an important variable which predicts employee engagement (Sarti, 2014), perhaps the mechanism that links supervisor support to employee engagement is something other than psychological empowerment. Perhaps the underlying mechanism that mediates supervisor support and employee engagement could be attributed to leader-member exchange (LMX), or satisfaction with the supervisor. For example, if employees have supportive supervisors, they become satisfied with their supervisors, which may make them engaged in their work. Likewise supportive supervisors encourage their subordinates, and foster confidence in them, which may lead employees to become engaged.

Hypothesis 2 stated that psychological empowerment (meaning, competence, selfdetermination, and impact) would mediate the relationship between opportunities for growth and employee engagement. The results of this study did not support the hypothesis in that psychological empowerment did not mediate the relationship between opportunities for growth and employee engagement. However, consistent with past findings showing that variables similar to opportunities for growth were related to employee engagement (Barbier et al., 2013; Xanthopoulou et al., 2009), opportunities for 
growth was directly related to employee engagement. It is reasonable to assume that if employees think their company offers opportunities for growth, they become engaged, but the underlying mechanism for such a relationship may not be psychological empowerment. Because empowerment is a psychological state (short-term), and opportunities for growth are long-term, the temporal difference in these variables may have caused the lack of support for psychological empowerment as a mediator. In other words, it may be difficult for employees who believe their organization provides opportunities for growth to become psychologically empowered because they may not experience the effects of these opportunities for growth immediately.

Hypothesis 3 stated that psychological empowerment (meaning, competence, selfdetermination, and impact) would mediate the relationship between core self-evaluations and employee engagement. Consistent with the hypothesis, results showed that psychological empowerment mediated the relationship between core self-evaluations and employee engagement. These results indicate that employees who felt positively about themselves and their capabilities became more psychologically empowered, which led them to become more engaged in their work. Although Jordan (2004) found a positive relationship between core self-evaluations and employee engagement, and Seibert, Wang, and Courtright (2011) found a positive relationship between positive self-evaluation traits (similar to core self-evaluations) and psychological empowerment, to date, no one else has examined the mediating role of psychological empowerment on the relationship between core self-evaluations and employee engagement. This study is the first to find 
that the underlying mechanism of the relationship between core self-evaluations and employee engagement is psychological empowerment.

Because Hypotheses 1 and 2 were not supported, additional analyses were conducted in order to examine if any individual dimension of psychological empowerment (impact, meaning, competence, and self-determination) might mediate the relationship between the three resources and employee engagement. Interestingly, results showed that the psychological empowerment dimension of meaning mediated the relationship between each of the resources and employee engagement. Meaning reflects the value of the work goal or purpose in relation to an individual's own sets of beliefs, values, and standards (Thomas \& Velthouse, 1990; Spreitzer, 1996). These results indicate that employees who have supportive supervisors, who believe that their company offers opportunities for growth, or feel positively about themselves and their capabilities are more likely to perceive that their work aligns with their personal beliefs and values, which, in turn, makes them become more engaged in their work. In other words, consistent across all resources in this study, if employees' work is positively affiliated with their personal set of values and beliefs, then they are more likely to become engaged in their work. It is reasonable to assume that employees may become motivated by and emotionally invested in work that is similar to their value set. The results of this study might suggest that meaning is a main underlying mechanism leading employees towards becoming engaged, given that they are provided with the necessary job and personal resources.

\section{Theoretical Implications}


Although results did not show that psychological empowerment mediates the relationship between job resources and employee engagement, it mediates the relationship between personal resources and employee engagement. Thus, the current study adds to the literature that psychological empowerment acts as a mediator not only for the relationship between job resources and employee engagement, but also for the relationship between personal resources (e.g., core self-evaluations) and employee engagement.

Another contribution of the present study is the finding that perhaps the dimension of meaning might be an important mediator on the relationship between job and personal resources with employee engagement. As previously explained, if employees' work is positively affiliated with their personal set of values and beliefs, then they are more likely to become engaged in their work. Meaning may have mediated the relationship between job and personal resources and employee engagement more than the other dimensions of psychological empowerment because it ties into an employees' personal value set. Unlike meaning, impact, competence, and self-determination all represent cognitive characteristics or characteristics of the nature and extent of one's work, whereas meaning has more of an emotional component. For example, employees' work may have a large impact in their department or organization, but if the work does not align with their personal set of beliefs and values, results would indicate they are less likely to become engaged in their work. Although psychological empowerment is considered a unitary construct (Spreitzer, 1995), given the present results, examining the 
way each component of psychological empowerment contributes to the prediction of work outcome variables or acts as a mediator might be beneficial.

\section{Practical Implications}

The results of the current study indicate that meaning seems to be an important mechanism of employees becoming engaged, given that they have job and personal resources in their work. Because of the numerous positive outcomes associated with employee engagement, and based on the results of the current study, organizations may want to place their employees into positions where the work is aligned with their personal value set in order to create meaning. Organizations may want to assess job candidates' beliefs and values, and use this information to place them in a position or create tasks or assignments that provide meaning.

Additionally, job seekers should look into organizations whose mission and purpose are closely aligned with their personal set of values and beliefs. Furthermore, given the positive and significant relationship between core self-evaluations and employee engagement, organizations might consider using a personality assessment when selecting their potential employees, in addition to traditional selection methods (e.g., interviews, cognitive ability tests). Moreover, given the significant and positive relationship between opportunities for growth and employee engagement, organizations would be wise to implement developmental and promotional strategies for their workforce such as training, internal recruiting and mobility programs, and succession planning. Knowing that the organization is committed to providing these opportunities 
for growth to their employees may lead them to become more engaged. These practical applications all may lead to higher employee engagement.

With respect to supervisor support, organizations would be wise to ensure that they are placing people in managerial roles who can support their direct reports. Due to the positive and significant relationship between supervisor support and employee engagement, meaning may play a role in leading employees with supportive supervisors to become engaged in their work. Supervisors who support their employees may foster meaning in their employees by connecting the goal of their work to the larger organizational mission and tying that into their employees' value set.

\section{Strengths, Weaknesses, and Future Direction for Research}

The current study had several strengths. First, this study addressed the potential underlying process of the relationship between resources and employee engagement. This process has been understudied. Furthermore, results of the study add to the literature that psychological empowerment acted as a mediator not only for the relationship between job resources and employee engagement, but also for the relationship between personal resources (e.g., core self-evaluations) and employee engagement. The present study is the first one that tested whether psychological empowerment would mediate the relationship between core self-evaluations and employee engagement. Thus, the main contribution of this study was identifying psychological empowerment as a significant mediator of the relationship between core self-evaluations and employee engagement. 
Second, when psychological empowerment was examined as a unitary construct (i.e., one single dimension), it did not mediate the relationship between two job resources (supervisor support and opportunities for growth) and employee engagement. However, when psychological empowerment was broken down into its components, results showed that meaning was a mechanism for the relationship between each of the resources and employee engagement. Future studies should look into the motivational aspects of meaning and how it can play a role in positive work outcomes such as performance, retention, and job satisfaction. Furthermore, more research attention could be focused on the psychological empowerment dimension of meaning, and the role that meaning plays with other predictors of employee engagement. Additionally, future research should also be directed at examining whether the other three components of psychological empowerment mediate the relationship between other resources and employee engagement.

Third, the present study had a wide range of participants in terms of their ages and work tenures. For example, age of participants in this study ranged from 21 years to 69 years, and job tenure ranged from less than one year to over 41 years. Additionally, there were a wide variety of industries represented in this sample. Given the diversity in these variables, participants might reflect the working population and thus the results of the present study might be generalizable to the current workforce.

Despite the strengths of this study, there are also design and methodological weaknesses. First, supervisor support and opportunities for growth were self-reported by participants, thus there may be potential bias in these responses due to the employees' 
relationship with their supervisor, or potentially being unaware of opportunities for growth offered by their organization. Future studies should attempt to objectively collect this sort of data, perhaps from organizations themselves. Supervisor support could potentially be measured based on responses from multiple employees reporting to a single supervisor, which may control for unique individual relationships with a supervisor. Second, the methodology of this study was non-experimental, and hence does not allow for causal inference to be made. Thus, one cannot say that job and personal resources cause employees to become psychologically empowered, which leads them to become more engaged in their work. Despite this weakness, several important inferences can be drawn about the relationships of these variables such that supervisor support, opportunities for growth, core-self evaluations, and psychological empowerment are all positively and significantly related to employee engagement. Additionally, two of the scales in this study were combined from different measures, which may present a weakness, given that other studies have never validated this combined scale with different samples. Despite this weakness, both of these scales had excellent internal consistency reliability. Future research may consider creating a new, valid scale for measuring supervisor support and opportunities for growth so that these variables can be measured in a way that allows for cross-study comparison and provides a single scale to use when measuring these types of job resources.

\section{Conclusion}

Given the positive outcomes of employee engagement, it is no wonder why organizations across the world try to engage their employees. Research has shown that 
personal and job resources are the main predictors of employee engagement. This study expanded that knowledge, and shed light on the underlying mechanism that employees with resources become engaged because they were psychologically empowered. Results of this study showed that psychological empowerment significantly mediated the relationship between core self-evaluations and employee engagement. Additionally, the psychological empowerment dimension of meaning acted as a mediator of the relationship between all of the resources in this study (supervisor support, opportunities for growth, and core self-evaluations) and employee engagement, indicating that meaning is an important variable for employees to become engaged. The findings of this study have important theoretical and practical applications by contributing to the existing body of literature on employee engagement, and providing guidance to both organizations and employees on how to foster employee engagement. 


\section{References}

Bakker, A. B., \& Bal, M. P. (2010). Weekly work engagement and performance: A study among starting teachers. Journal of Occupational and Organizational Psychology, 83, 189-206.

Bakker, A. B., \& Leiter, M. P. (Eds.). (2010). Work engagement: A handbook of essential theory and research. Psychology Press.

Bakker, A. B., \& Demerouti, E. (2007). The job demands-resources model: State of the art. Journal of Managerial Psychology, 22, 309-328.

Bakker, A. B., \& Demerouti, E. (2008). Towards a model of work engagement. Career Development International, 13, 209-223.

Bakker, A. B., Demerouti, E., \& Verbeke, W. (2004). Using the job demands-resources model to predict burnout and performance. Human Resource Management, 43, 83-104.

Bakker, A. B., Schaufeli, W. B., Leiter, M. P., \& Taris, T. W. (2008). Work engagement: An emerging concept in occupational health psychology. Work \& Stress, 22, 187200.

Bandura, A. (1997). Self-efficacy: The exercise of control. John Wiley \& Sons, Inc.

Barbier, M., Hansez, I., Chmiel, N., \& Demerouti, E. (2013). Performance expectations, personal resources, and job resources: How do they predict work engagement?. European Journal of Work and Organizational Psychology, 22, 750-762.

Bhatnagar, J. (2012). Management of innovation: Role of psychological empowerment, work engagement and turnover intention in the Indian context. The International Journal of Human Resource Management, 23, 928-951.

Combs, J., Liu, Y., Hall, A., \& Ketchen, D. (2006). How much do high-performance work practices matter? A meta-analysis of their effects on organizational performance. Personnel Psychology, 59, 501-528.

Costa, P. T., \& MacCrae, R. R. (1992). Revised NEO personality inventory (NEO PI-R) and NEO five-factor inventory (NEO FFI): Professional manual. Psychological Assessment Resources.

Crabtree, S. (2013, October 08). Worldwide, 13\% of Employees Are Engaged At Work. Retrieved July, 2015, from http://www.gallup.com/poll/165269/worldwideemployees-engaged-work.aspx 
Gierveld, J. H., \& Bakker, A. B. (2005). De invloed van de secretaresse [The influence of the secretary]. Diemen, The Netherlands: Manpower.

Halbesleben, J. R. (2010). A meta-analysis of work engagement: Relationships with burnout, demands, resources, and consequences. Work Engagement: A Handbook of Essential Theory and Research, 8, 102-117.

Harter, J. K., Schmidt, F. L., \& Hayes, T. L. (2002). Business-unit-level relationship between employee satisfaction, employee engagement, and business outcomes: A meta-analysis. Journal of Applied Psychology, 87, 268.

Harter, S. (1990). Self and identity development.

Hayes, A. F., \& Preacher, K. J. (2014). Statistical mediation analysis with a multicategorical independent variable. British Journal of Mathematical and Statistical Psychology, 67(3).

Hobfoll, S. E. (2011). Conservation of resource caravans and engaged settings. Journal of Occupational and Organizational Psychology, 84(1), 116-122.

Jordan, A. M. (2014). Employee engagement and individual differences: An empirical examination of Kahn's theory - a cognitive-motivational model. Capella University Dissertation.

Judge, T. A., Erez, A., \& Bono, J. E. (1998). The power of being positive: The relation between positive self-concept and job performance. Human Performance, 11, 167-187.

Judge, T. A., Erez, A., Bono, J. E., \& Thoresen, C. J. (2002). Are measures of selfesteem, neuroticism, locus of control, and generalized self-efficacy indicators of a common core construct?. Journal of Personality and Social Psychology, 83, 693.

Judge, T. A., Locke, E. A., \& Durham, C. C. (1997). The dispositional causes of job satisfaction: A core evaluations approach. Research in Organizational Behavior, 19(19), 151-188.

Judge, T. A., Locke, E. A., Durham, C. C., \& Kluger, A. N. (1998). Dispositional effects on job and life satisfaction: the role of core evaluations. Journal of Applied Psychology, 83, 17.

Kahn, W. A. (1990). Psychological conditions of personal engagement and disengagement at work. Academy of Management Journal, 33, 692-724.

Karasek Jr, R. A. (1979). Job demands, job decision latitude, and mental strain: Implications for job redesign. Administrative Science Quarterly, 285-308. 
Luthans, F., \& Youssef, C. M. (2007). Emerging positive organizational behavior. Journal of Management, 33, 321-349.

Macey, W. H., \& Schneider, B. (2008). The meaning of employee engagement. Industrial and Organizational Psychology, 1, 3-30.

Macsinga, I., Sulea, C., Sârbescu, P., Fischmann, G., \& Dumitru, C. (2015). Engaged, committed and helpful employees: The role of psychological empowerment. The Journal of Psychology, 149, 263-276.

May, D. R., Gilson, R. L., \& Harter, L. M. (2004). The psychological conditions of meaningfulness, safety and availability and the engagement of the human spirit at work. Journal of Occupational and Organizational Psychology, 77(1), 11-37.

Pfeffer, J. (1998). The human equation: Building profits by putting people first. Harvard Business Press. Brighton, Massachusetts.

Pocnet, C., Antonietti, J. P., Massoudi, K., Györkös, C., Becker, J., de Bruin, G. P., \& Rossier, J. (2014). Influence of individual characteristics on work engagement and job stress in a sample of national and foreign workers in Switzerland. Swiss Journal of Psychology. 74, 17-27.

Quiñones, M., Van den Broeck, A., \& De Witte, H. (2013). Do job resources affect work engagement via psychological empowerment? A mediation analysis. Revista de Psicología del Trabajo y de las Organizaciones, 29(3), 127.

Roberts, D. R., \& Davenport, T. O. (2002). Job engagement: Why it's important and how to improve it. Employment Relations Today, 29(3), 21-29.

Rotter, J. B. (1966). Generalized expectancies for internal versus external control of reinforcement. Psychological Monographs: General and Applied, 80, 1.

Saks, A. M. (2006). Antecedents and consequences of employee engagement. Journal of Managerial psychology, 21, 600-619.

Sarti, D. (2014). Job resources as antecedents of engagement at work: Evidence from a long-term care setting. Human Resource Development Quarterly, 25, 213-237.

Schaufeli, W. B., \& Bakker, A. B. (2004). Job demands, job resources, and their relationship with burnout and engagement: A multi-sample study. Journal of Organizational Behavior, 25, 293-315.

Schaufeli, W. B., Salanova, M., González-Romá, V., \& Bakker, A. B. (2002). The measurement of engagement and burnout: A two sample confirmatory factor analytic approach. Journal of Happiness Studies, 3, 71-92. 
Seibert, S. E., Wang, G., \& Courtright, S. H. (2011). Antecedents and consequences of psychological and team empowerment in organizations: A meta-analytic review. Journal of Applied Psychology, 96, 981.

Spreitzer, G. M. (1995). Psychological empowerment in the workplace: Dimensions, measurement, and validation. Academy of Management Journal, 38, 1442-1465.

Thomas, K. W., \& Velthouse, B. A. (1990). Cognitive elements of empowerment: An "interpretive" model of intrinsic task motivation. Academy of Management Review, 15, 666-681.

Weigl, M., Hornung, S., Parker, S. K., Petru, R., Glaser, J., \& Angerer, P. (2010). Work engagement accumulation of task, social, personal resources: A three-wave structural equation model. Journal of Vocational Behavior, 77, 140-153.

Xanthopoulou, D., Bakker, A. B., Demerouti, E., \& Schaufeli, W. B. (2007). The role of personal resources in the job demands-resources model. International Journal of Stress Management, 14, 121.

Xanthopoulou, D., Bakker, A. B., Demerouti, E., \& Schaufeli, W. B. (2009). Reciprocal relationships between job resources, personal resources, and work engagement. Journal of Vocational Behavior, 74, 235-244.

Zacharatos, A., Barling, J., \& Iverson, R. D. (2005). High-performance work systems and occupational safety. Journal of Applied Psychology, 90, 77. 


\section{Appendix}

Survey Items

Psychological Empowerment (Spreitzer, 1995)

1. The work I do is very important to me.

2. My job activities are personally meaningful to me.

3. My work is meaningful to me.

4. I am confident about my abilities to do my job.

5. I am self-assured about my capabilities to perform my work activities.

6. I have mastered the skills necessary for my job.

7. I have significant autonomy in determining how I do my job.

8. I can decide on my own how I go about doing my work.

9. I have considerable opportunity for independence and freedom in how I do my job.

10. My impact on what happens in my department in large.

11. I have a great deal of control over what happens in my department.

12. I have significant influence over what happens in my department.

Employee Engagement - Utrecht Work Engagement Scale (Schaufeli \& Bakker, $\underline{2003)}$

1. At my work, I feel bursting with energy.

2. At my job, I feel strong and vigorous.

3. When I get up in the morning, I feel like going to work.

4. I can continue working for very long periods of time.

5. At my job I am mentally resilient.

6. I find the work that I do full of meaning and purpose.

7. I am enthusiastic about my job.

8. My job inspires me.

9. I am proud of the work that I do.

10. To me, my job is challenging.

11. Time flies when I'm working.

12. I forget everything else around me when I'm working.

13. I feel happy when I am working intensely.

14. At times, I am immersed in my work.

15. I get carried away when I am working.

Core Self-Evaluations - The Core Self-Evaluations Scale (Judge, Erez, Bono, Thoresen, 2003)

1. I am confident I get the success I deserve in life.

2. Sometimes I feel depressed. (r) 
3. When I try, I generally succeed.

4. Sometimes when I fail I feel worthless. (r)

5. I complete tasks successfully.

6. Sometimes, I do not feel in control of my work. (r)

7. Overall, I am satisfied with myself.

8. I am filled with doubts about my competence. (r)

9. I determine what will happen in my life.

10. I do not feel in control of my success in my career. (r)

11. I am capable of coping with most of my problems.

12. There are times when things look pretty bleak and hopeless to me. (r)

Opportunities for Growth - Organizational Support for Development (Kraimer, Seibert, Wayne, Linden, \& Bravo, 2011)

1. My organization has programs and policies that help employees advance in their functional specialization.

2. My organization provides opportunities for employees to develop their specialized functional skills.

3. My organization has programs and policies that help employees reach higher levels within the organization.

4. My organization has career development programs that help employees develop their skills and expertise.

Opportunities for Growth - Opportunities for Development Scale (Bakker \& Bal, $\underline{2010)}$

1. My work offers me the opportunity to learn new things.

2. I have sufficient possibilities to develop myself at work.

3. I have the opportunity to grow my strengths.

Supervisor Support - Supervisor Support Scale (Cheng, Jiang, Cheng, Riley, \& $\underline{\text { Jen, 2015) }}$

1. My supervisor shows concern for me.

2. My supervisor expresses an interest in my personal well-being.

3. My supervisor helps employees to develop their strengths.

Supervisor Support - Perceived Supervisor Support Scale Adapted (Swanberg, McKechnie, Ojha, \& James, 2011)

1. My supervisor is supportive when I have a work problem.

2. My supervisor cares about the effect that work demands have on my personal and family life.

3. My supervisor recognizes when I do good work. 
4. My supervisor encourages me to come up with new and better ways of doing things.

5. My supervisor allows me to make decisions necessary to do my job well.

Demographic Information

1. What is your age (in years)?

2. What ethnicity do you identify with? (You may select more than one answer)

- Hispanic or Latino

- American Indian or Alaska Native

- Asian

- Black or African American

- Native Hawaiian or Pacific Islander

- White

3. What is your current employment status?

- Full-time employee

- Part-time employee

- Contract/Temp worker

4. How many MONTHS have you been in your current job?

5. Please select the industry that best describes the organization that you currently work for.

- Arts and Entertainment

- Construction

- Education

- Financial services or Banking

- Government

- Healthcare

- Hospitality and Leisure

- Manufacturing

- Media

- Professional/Business Services

- Restaurant/Food Service

- Retail

- Technology

- Utilities and Energy

- Other

6. Are you a supervisor? (i.e., do you have people who work under you)

- Yes

- No 